\title{
Optimalisasi Rekam Jejak Perkuliahan Dosen-Mahasiswa Menggunakan Berita Acara Perkuliahan (BAP) Online
}

\author{
Rati Kumalasari ${ }^{1}$, Sriasih², Lucia Sri Istiyowati ${ }^{3}$, Yunus Widjaja ${ }^{4}$ \\ STMIK Mataram ${ }^{1,2}$ \\ Perbanas Institute ${ }^{3}$ \\ Atma Jaya Indonesia Catholic University ${ }^{4}$ \\ sriasih.amikom@gmail.com²
}

\begin{abstract}
Abstrak - Perkembangan teknologi informasi dalam bidang pendidikan dan pengajaran memicu lembaga pendidikan untuk terus meningkatkan sarana dan prasarana penunjangnya agar penyelenggaraan pendidikan dan pengajaran berjalan dengan baik. Terlebih lagi pada perguruan tinggi, baik swasta maupun negeri. Pada bidang pengajaran, diperlukan pengontrolan yang baik agar arah materi pelajaran yang diajarkan dosen tidak menyimpang dengan rancangan materi yang telah disusun atau yang disebut Satuan Acara Perkuliahan. Pada Sekolah Tinggi Manajemen Informatika Komputer Mataram pengontrolan itu dilakukan dengan menggunakan Berita Acara Perkuliahan (BAP). Untuk meningkatkan efektifitas dan efisiensi pengontrolan, maka BAP pun dapat dibuat dengan memanfaatkan teknologi informasi yang ada. BAP Online adalah solusi tepan untuk mempermudah dan meningkatkan kinerja Bagian Akademik. BAP ini terkoneksi ke Server sehingga dapat dikontrol melalui satu computer yang tersedia kapan saja dan dimana saja.
\end{abstract}

Kata Kunci: Berita Acara Perkuliahan, BAP, Online

\section{Latar Belakang}

Perkembangan teknologi informasi dalam bidang pendidikan dan pengajaran memicu lembaga pendidikan untuk terus meningkatkan sarana dan prasarana penunjangnya agar penyelenggaraan pendidikan dan pengajaran berjalan dengan baik. Terlebih lagi pada perguruan tinggi, baik swasta maupun negeri. Pada bidang pengajaran, diperlukan pengontrolan yang baik agar arah materi pelajaran yang diajarkan dosen tidak menyimpang dengan rancangan materi yang telah disusun atau yang disebut Satuan Acara Perkuliahan. Pada Sekolah Tinggi Manajemen Informatika Komputer (STMIK) Mataram pengontrolan itu dilakukan dengan menggunakan Berita Acara Perkuliahan (BAP). Untuk meningkatkan efektifitas dan efisiensi pengontrolan, maka BAP pun dapat dibuat dengan memanfaatkan teknologi informasi yang ada.

Pada STMIK Mataram, BAP dibuat dengan dicetak pada kertas dan di isi oleh setiap dosen pada setiap jam mengajar dosen. Dengan demikian maka jumlah BAP yang dicetak adalah sejumlah matakuliah dikalikan jumlah kelas yang ada, sehingga akan menghabiskan banyak kertas. Akibatnya setiap semesternya lembaga membutuhkan tidak sedikit dana hanya untuk mencetak BAP. Selain itu, dari BAP inilah Bagian Administrasi melakukan pengecekan kehadiran dosen mengajar untuk selanjutnya dilakukan rekap gaji. Dengan banyaknya BAP yang harus diperiksa oleh Bagian Administrasi maka itu akan memperlambat kinerja Bagian Administrasi dalam melakukan rekap gaji, akibatnya jika terjadi keterlambatan dalam menyelesaikan rekap maka gaji dosen akan terlambat pula. BAP memiliki peranan yang sangat penting dalam mengontrol arah perkuliahan agar sesuai dengan rancangan materi perkuliahan atau Satuan Acara Perkuliahan, juga mengontrol kehadiran dosen mengajar.

Guna meningkatkan efisiensi pengontrolan melalui BAP tersebut serta memudahkan dalam perekapan data dosen mengajar, maka dibutuhkan suatu sistem BAP yang terkomputerisa berbasis web. Dengan adanya sistem ini diharapkan proses pengontrolan dan perekapan data kehadiran dosen mengajar dapat dilakukan dengan cepat dan mudah.

\section{Kajian Pustaka}

\section{a. Sistem Informasi Berita Acara Perkuliahan (BAP) Online}

Sistem informasi adalah suatu system didalam suatu organisasi yang mempertemukan kebutuhan pengolahan transaksi harian yang mendukung fungsi operasi organisasi yang bersifat manajerial dengan kegiatan strategi dari suatu organisasi untuk dapat menyediakan 
kepada pihak luar tertentu dengan laporanlaporan yang diperlukan (Sutabri, 2012).

Sistem Informasi BAP Online adalah system informasi yang dapat digunakan untuk merekam semua kegiatan atau Berita Acara Perkuliahan yang dilakukan oleh dosen pengajar matakuliah pada STMIK Mataram. Sistem dapat mempermudah bagian Akademik untuk memantau perkembangan belajar mengajar yang dilakukan oleh masing-masing dosen. Dengan demikian semu proses belajar mengajar akan lebih efisien sehingga mencapai target mengajar seperti yang direncanakan dalam Satuan Acara Perkuliahan.

\section{b. Unified Modelling Language (UML)}

Untuk pengembangan sistem monitoring pengiriman hadiah langsung TPRT, penulis memilih metodologi Object Oriented Programming(OOP) yang mana menggunakan Unified Modeling Language (UML) sebagai metode untuk melakukan analisa dan membangun sistem. UML adalah 'bahasa' pemodelan standar untuk melakukan spesifikasi, konstruksi, visualisasi dan dokumentasi perangkat lunak. UML menjadi standar bahasa pemodelan untuk aplikasi berorientasi objek bermula pada tahun 1997 dengan munculnya UML versi 1.1 oleh Booch, Rumbaugh dan Jacobson yang menyusun tiga buku serial tentang UML pada tahun 1999.

Faktor yang mendorong terbentuknya UML adalah pentingnya model, karena model merupakan dasar untuk membentuk sistem yang baik. Tanpa model akan sulit menjelaskan dan menggambarkan suatu sistem perangkat lunak, terutama perangkat lunak yang komplek serta diperlukannya teknik atau metoda untuk rekayasa software agar perangkat lunak yang dibuat berkualitas serta mempersingkat biaya dan tenaga dalam rekayasa perangkat lunak (Sutanta edhy, 2003).

$$
\text { Pada perkembangan teknik }
$$

pemrograman beorientasi objek, munculah sebuah standarisasi bahasa pemodelan untuk pembangunan perangkat lunak yang dibangun dengan teknik pemrograman berorientasi objek, yaitu Unifed Modeling Languange (UML).UML muncul karena adanya kebutuhan pemodelan visual untuk menspesifikasikan, menggambarkan, membangun, dan dokumentasi dari sistem peranggkat lunak. UML merupakan bahasa visual untuk pemodelan dan komunikasi mengenai sebuah sistem dengan menggunakan diagram dan teks-teks pendukung. UML hanya berfungsi untuk melakukan pemodelan.Jadi penggunaan UML tidak terbatas pada metodelogi tertentu, meskipun pada kenyataanya UML paling banyak digunakan pada metodelogi berorientasi objek (Shalahuddin, 2013).

Unified Modelling Language (UML) adalah bahasa untuk menspesifikasi, memvisualisasikan, serta mengkonstruksi bangunan dasar system perangkat lunak, termasuk melibatkan pemodelan aturan-aturan bisnis (Nugroho, 2011).

\section{c. Hypertext Preprocessor (PHP)}

Hypertext Preprocessor Merupakan bahasa pemrograman berbasis web memiliki kemampuan untuk memroses dan mengolah data secara dinamis. PHP dapat dikatakan sebagai sebuah server-side emmbedded script language, artinya semua sintaks dan perintah program yang anda tulis akan sepenuhnya dijalankan oleh server, tetapi dapat disertakan pada halaman HTML biasa. Pada umumnya semua aplikasi browser, tetapi prosesnya secara keseluruhan dijalankan pada server (Agus, 2008).

\section{d. Entity Relationship Diagram (ERD)}

Entity Relationship Diagram merupakan suatu model jaringan yang menggunakan susunan data yang disimpan dalam sistem secara abstrak (Ladjamudin, 2005). Penggunaan simbol yang menggambarkan 3 informasi yaitu, entity, Atribut, dan relasi. Pada ERD, terdapat beberapa bentuk relasi yang dapat terjadi antar entitas, yaitu, Relasi One-to-One, Relasi One-toMany, Relasi Many-to-One, dan Relasi Many-toMany

\section{Perancangan Sistem}

a. Unified Modeling Language (UML) 1) Use Case Diagram

Pada Use Case Diagram digambarkan hubungan antara sistem dengan pengguna system, adapun Use Case Diagram sistem informasi BAP ini dapat dilihat pada gambar 3.1 berikut. 


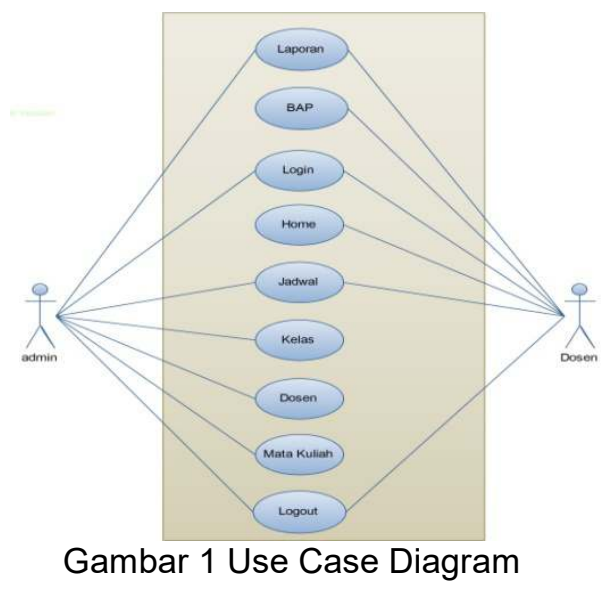

Pada gambar 1 dapat kita perhatikan bahwa admin merupakan pengontol dari semua system yang ada. Admin dapat melakukan manipulasi dan pengolahan data di semua sub system. Sedangkan dosen hanya dapat melakukan pengolahan data terkait dengan berita acara perkuliahan yang sedang atau akan dilaksanakan.

\section{2) Activity Diagram}

Activity Diagram menggambarkan aktivitas system berdasarkan sub kegiatan atau keseluruhan kegiatan yang dilakukan. Adapun Activity Diagram system ini dapat dilihat pada gambar 3.2 berikut.

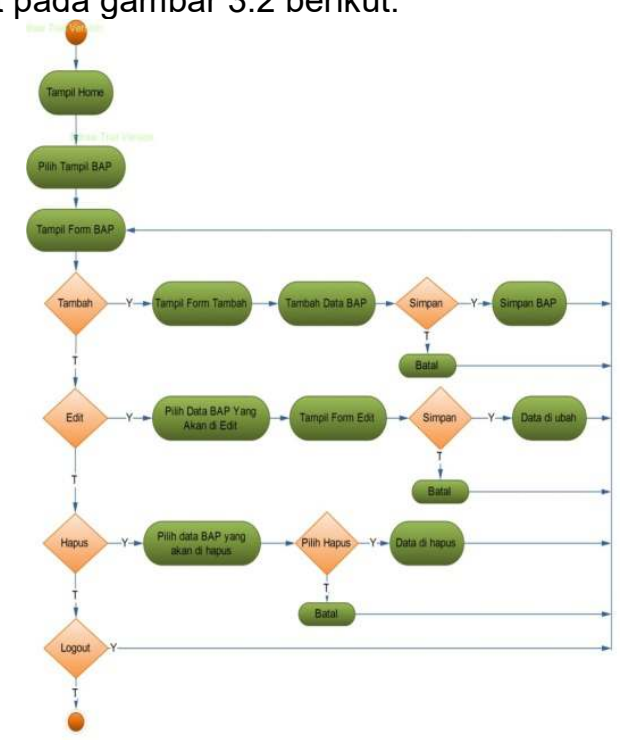

Gambar 2 Activity Diagram BAP

Activity Diagram pada gambar 2 menggambarkan bagaina proses pengolahan data BAP dilakukan oleh system, mulai dari tahap awal hingga semua proses perekaman terhadap proses belajar mengajar dosen dan mahasiswa terekam di system.

\section{3) Entity Relationship Diagram (ERD)}

$$
\text { Entity Relationship Diagram }
$$

(ERD) menggambarkan bagaimana hubungan atara setiap table database yang ada pada system informasi ini. Adapun ERD pada system informasi BAP online ini dapat dilihat pada gambar 3 berikut.

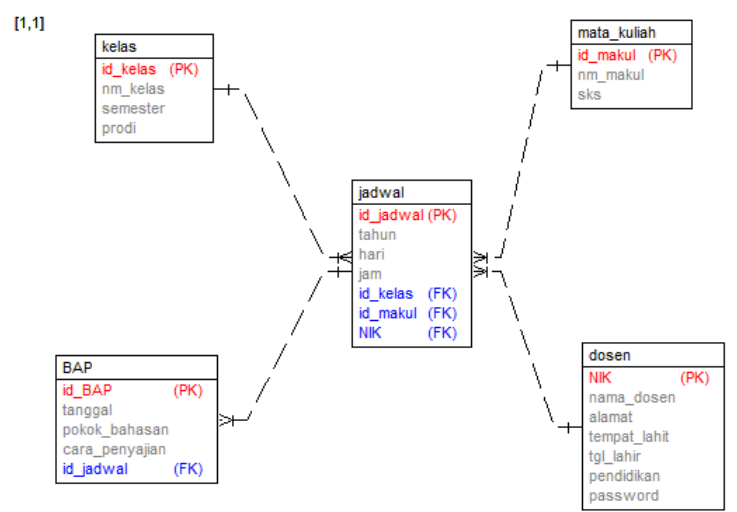

Gambar 3 Entity Relationship Diagram Pada gambar 3 dapat kita lihat bahwa setiap table pada database system ini terhubung satu sama lain, baik itu table kelas, mata kuliah, dosen, jadwal dan BAP. Dengan demikian data dari setiap table akan mudah di sinkronisasikan.

\section{Implementasi Sistem dan hasil \\ a. Halaman Utama}

Tampilan pertama pada program Berita Acara Perkuliahan Berbasis Web Pada AMIKOM Mataram menampilkan menu yang terdiri dari home, about, login dosen dan calender. Pada halaman inilah pengguna menginputkan username dan password untuk dapat memasuki sistem.

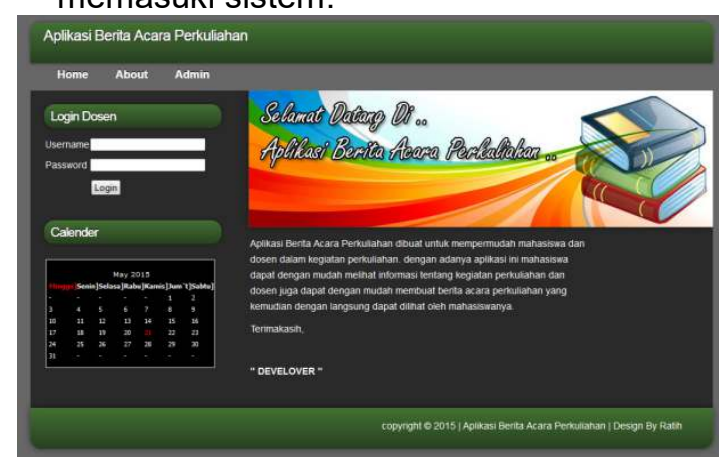

Gambar 4 Halaman Utama 


\section{b. Tampilan Halaman Data BAP}

Halaman ini menampilkan data Berita Acara Perkuliahan yang sudah diinputkan oleh admin ke dalam data BAP dan terdapat proses tambah, edit dan hapus data.

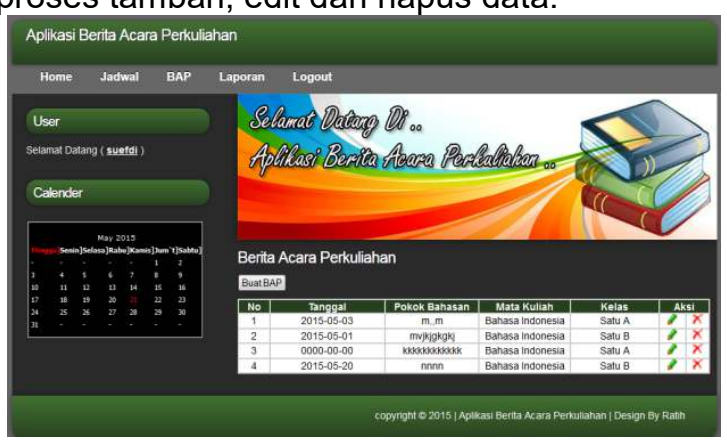

Gambar 5 Halaman Data BAP

\section{c. Form Tambah Data BAP}

Halaman ini berfungsi untuk menambah data Berita Acara Perkuliahan yang diinputkan adalah Id_jadwal, tanggal, pokok bahasan, cara penyajian, jika ingin di simpan pilih tombol simpan dan jika tidak pilih batal.

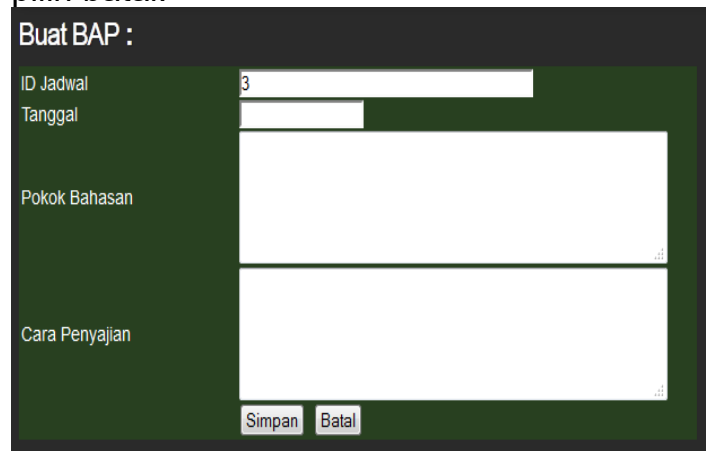

Gambar 6 Form Tambah Data BAP

\section{d. Tampilan Halaman Cetak Laporan BAP}

Halaman ini menampilkan cetak laporan Berita Acara Perkuliahan berdasarkan id jadwal untuk mencetak laporan BAP.

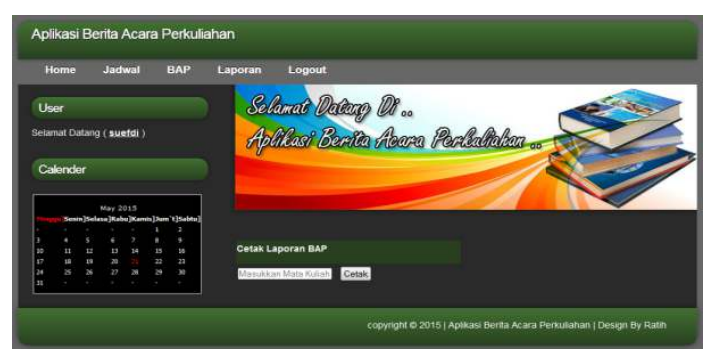

Gambar 7 Halaman Cetak Laporan BAP

\section{Kesimpulan}

Dari pembahasan mengenai kesimpulan Aplkasi Berita Acara Perkuliahan Amikom Mataram, maka penulis menyimpulkan bahwa Dengan adanya Aplikasi Berita Acara Perkuliahan maka proses pengolahan data BAP, dosen, kelas, jadwal dan mata kuliah dapat dilakukan dengan cepat, mudah dan lebih baik dari sebelumnya. Pengolahan data berita acara perkuliahan yang lebih baik akan memudahkan dalam hal pengambilan keputusan sehingga dapat meningkatkan kinerja yang lebih tinggi lagi.

\section{Daftar Pustaka}

Agus, B. (2008). PHP Script Most Wanted. Yogyakarta: Andi Offset.

Ladjamudin, A.-B. b. (2005). Analisis dan Desain Sistem Informasi. Yogyakarta: Graha IImu.

Nugroho, A. (2011). Perancangan dan Implementasi Sistem Basis Data. Yogyakarta: Andi.

Shalahuddin, R. (2013). Rekayasa Perangkat lunak Terstruktur dan Berorientasi Objek. Bandung: Informatika.

Sutabri, T. (2012). Konsep Sistem Informasi. Yogyakarta: Andi Offset.

Sutanta edhy, S. (2003). Sistem Informasi Manajemen. Yogyakarta: Graha IImu. 